\title{
Extremophilic nitrite-oxidizing Chloroflexi from Yellowstone hot springs
}

\author{
Eva Spieck $\mathbb{D}^{1} \cdot$ Michael Spohn $^{2} \cdot$ Katja Wendt $^{1} \cdot$ Eberhard Bock $^{1} \cdot$ Jessup Shively $^{3} \cdot$ Jeroen Frank $^{4,5}$. \\ Daniela Indenbirken ${ }^{2} \cdot$ Malik Alawi $\mathbb{1}^{6} \cdot$ Sebastian Lücker $\mathbb{1}^{4} \cdot$ Jennifer Hüpeden ${ }^{1}$
}

Received: 26 February 2019 / Revised: 3 August 2019 / Accepted: 6 September 2019 / Published online: 17 October 2019

(c) The Author(s), under exclusive licence to International Society for Microbial Ecology 2019

\begin{abstract}
Nitrifying microorganisms occur across a wide temperature range from 4 to $84{ }^{\circ} \mathrm{C}$ and previous studies in geothermal systems revealed their activity under extreme conditions. Archaea were detected to be responsible for the first step of nitrification, but it is still a challenging issue to clarify the identity of heat-tolerant nitrite oxidizers. In a long-term cultivation approach, we inoculated mineral media containing ammonium and nitrite as substrates with biofilms and sediments of two hot springs in Yellowstone National Park (USA). The nitrifying consortia obtained at $70{ }^{\circ} \mathrm{C}$ consisted mostly of novel Chloroflexi as revealed by metagenomic sequencing. Among these, two deep-branching novel Chloroflexi were identified as putative nitrite-oxidizing bacteria (NOB) by the presence of nitrite oxidoreductase encoding genes in their genomes. Stoichiometric oxidation of nitrite to nitrate occurred under lithoautotrophic conditions, but was stimulated by organic matter. Both NOB candidates survived long periods of starvation and the more abundant one formed miniaturized cells and was heat resistant. This detection of novel thermophilic NOB exemplifies our still incomplete knowledge of nitrification, and indicates that nitrite oxidation might be an ancient and wide-spread form of energy conservation.
\end{abstract}

\section{Introduction}

Nitrification, the biological conversion of ammonia to nitrite and nitrate, is a fundamental process of the global nitrogen

Supplementary information The online version of this article (https:// doi.org/10.1038/s41396-019-0530-9) contains supplementary material, which is available to authorized users.

Eva Spieck

eva.spieck@uni-hamburg.de

1 Department of Microbiology and Biotechnology, Universität Hamburg, Hamburg, Germany

2 Technology Platform Next Generation Sequencing, Heinrich Pette Institut, Hamburg, Germany

3 Department of Genetics and Biochemistry, Clemson University, Clemson, SC, USA

4 Department of Microbiology, IWWR, Radboud University, Nijmegen, The Netherlands

5 Soehngen Institute of Anaerobic Microbiology, Radboud University, Nijmegen, The Netherlands

6 Bioinformatics Core, University Medical-Center HamburgEppendorf, Hamburg, Germany cycle and must be sustained in engineered and natural environments including those with extreme conditions. Ammonia and nitrite oxidation are accomplished by a number of highly specialized nitrifiers, adapted to a wide temperature spectrum [1, 2]. Described nitrite-oxidizing bacteria (NOB) are scattered among the Alpha-, Beta-, and Gammaproteobacteria $[1,3]$ or belong to the distinct bacterial phyla Nitrospirae and Nitrospinae [4, 5]. With the isolation of the moderately thermophilic nitrite oxidizer Nitrolancea affiliated with the phylum Chloroflexi [6], it became obvious that the diversity of NOB is even more complex than previously thought.

Geothermal settings are suitable habitats for a highly active nitrogen cycle and process measurements revealed nitrogen fixation, ammonia oxidation, denitrification and nitrate reduction to ammonium in US hot springs [7, 8]. Chemolithotrophic microorganisms are important primary producers in high-temperature environments [9] and ammonia oxidation may be a major source for biomass production [10]. The ammonia-oxidizing archaeon (AOA) "Candidatus Nitrosocaldus yellowstonii" with a growth optimum of $72{ }^{\circ} \mathrm{C}$ has been isolated from a hot spring in Yellowstone National Park (YNP) [11]. Additional thermophilic AOA from the Nitrosocaldus clade were described 
recently [12, 13]. Although nitrate formation could be measured in geothermal areas of Iceland and Kamchatka [2] and calculations of energy yields confirmed that both steps of nitrification are thermodynamically feasible in hot springs [10], nitrite-oxidizing microorganisms have not yet been identified in these systems. Instead, it was speculated that in geothermal springs nitrite was removed by anaerobic respiration [14].

Evidence for nitrite oxidation at elevated temperatures was brought by molecular detection and enrichment of Nitrospira, but the temperature optimum of such cultures was in the range of $37-52^{\circ} \mathrm{C}$ [15-17]. To elucidate the microorganisms responsible for nitrite oxidation in geothermal settings, cultured representatives are valuable to gain a deeper understanding of the physiological and genomic potential of these to date unidentified species. Although the geothermal area in YNP is a "hot spot" for the detection of novel microorganisms [18-20], thermophilic NOB with a temperature optimum above $52{ }^{\circ} \mathrm{C}$ have not been identified so far. Long-term cultivation and metagenomics listed several bacterial and archaeal candidates for nitrite oxidation in high-temperature bioreactors, but the diverse community impeded identification of single microbes [21]. Just recently, thermophilic, putative nitrite oxidoreductase (NXR)-containing Chloroflexi were enriched along with Nitrosocaldus islandicus [13]. In this study we present first culture-dependent and genome-based insights on microorganisms that drive nitrite oxidation at high temperature.

\section{Materials and methods}

\section{Sampling}

Sampling was performed in September 2007 at YNP UWG009 Spring (Lat: 44.4795014, Lon: -110.8518253) and YNP Diadem Spring (Lat: 44.5600075, Lon: -110.8328473) in the Upper and Lower Geyser Basin of YNP. Both nonsulfurous springs are characterized by slightly alkaline to neutral $\mathrm{pH}$ values of 8.0 and 7.1 and vent temperatures of $92{ }^{\circ} \mathrm{C}$ and $74^{\circ} \mathrm{C}$, respectively (Table S1). UWG009 harbors microbial mats of different colors on the shore (Fig. S1a, b), whereas gray to brownish sediment was sampled from Diadem Spring with a strong acclivity (sampling spots Yell 4-Yell 6; Fig. S1c). The temperatures at the sampling sites were $63{ }^{\circ} \mathrm{C}$ and $59{ }^{\circ} \mathrm{C}$, respectively (Table S2).

\section{Cultivation media}

For enrichment of nitrifying microorganisms, either unbuffered mineral medium for ammonia-oxidizing bacteria (AOB) with $0.5 \mathrm{mM}$ ammonium chloride [22] or a mineral NOB medium with $0.3 \mathrm{mM}, 1 \mathrm{mM}$, or $3 \mathrm{mM}$ sodium nitrite
[23] was used. Since 2015, the NOB medium was prepared with a modified trace element solution [24]. Half-strength R2A media consisted of $0.25 \mathrm{~g}$ yeast extract, $0.25 \mathrm{~g}$ proteose peptone, $0.25 \mathrm{~g}$ casamino acids, $0.25 \mathrm{~g}$ glucose, $0.25 \mathrm{~g}$ soluble starch, $0.25 \mathrm{~g}$ Na-pyruvate, $0.15 \mathrm{~g} \mathrm{~K}_{2} \mathrm{HPO}_{4}, 0.025 \mathrm{~g}$ $\mathrm{MgSO}_{4} \times 7 \mathrm{H}_{2} \mathrm{O}$, dissolved in $1 \mathrm{~L}$ distilled water. The final $\mathrm{pH}$ was adjusted to 7.2 with crystalline $\mathrm{KH}_{2} \mathrm{PO}_{4}$ and autoclaved for $15 \mathrm{~min}$ at $121{ }^{\circ} \mathrm{C}$. R2A plates were prepared by adding $13 \mathrm{~g} \mathrm{~L}^{-1}$ agarose, nitrite $(0.125 \mathrm{mM})$ and ammonium (1 mM). HWB medium (half-strength) was composed of $0.25 \mathrm{~g} \mathrm{~L}^{-1}$ peptone, $0.25 \mathrm{~g} \mathrm{~L}^{-1}$ yeast extract, $0.25 \mathrm{~g} \mathrm{~L}^{-1}$ meat extract, $0.292 \mathrm{~g} \mathrm{~L}^{-1}$ sodium chloride, $\mathrm{pH}$ 7.3-7.4.

\section{Enrichment}

The samples were transported at ambient temperature by courier to the University of Hamburg (Germany). A sample aliquot of $0.5 \mathrm{ml}$ (spring water with biofilm or sediment) was inoculated into $100 \mathrm{ml}$ screw cap Schott bottles, containing $50 \mathrm{ml}$ of mineral medium. Cultures were incubated at $70{ }^{\circ} \mathrm{C}\left( \pm 2{ }^{\circ} \mathrm{C}\right)$ and evaporation was compensated for with sterile distilled water. All batch cultures were grown under static conditions. When ammonium was depleted, it was replenished to $400-500 \mu \mathrm{M}$ with sterile $5 \mathrm{M}$ ammonium chloride solution. Ammonium measurements were done with Quantofix test stripes (Macherey-Nagel, Düren, Germany). The $\mathrm{pH}$ value was manually adjusted with $5 \%$ $\mathrm{NaHCO}_{3}$ to about 7.4. Cultures were transferred with 1-2\% (v/v) inoculum. Since 2011, culturing was continued in 100-300 ml Erlenmeyer flasks at a reduced temperature of $60-65^{\circ} \mathrm{C}$ to enhance growth. In Fig. S2, the enrichment procedure is exemplarily shown for culture Yell 2.

In 2015, a follow-up culture of A6 (derived from original culture Yell 2, Fig. S2) was supplemented with nitrite and formate. After 5 months, the nitrifying culture was inoculated into autotrophic NOB medium (containing additionally 0.5 $\mathrm{mM}$ ammonium), which was mixed with half-strength R2A medium (initially 1:5 diluted with NOB medium, later 1:10). Subsequently, cultures were fed with nitrite when it was consumed and ammonium (as N-source) when growth ceased.

\section{Microscopic investigations}

For electron microscopy, cells were collected, fixed with $2.5 \%$ (v/v) glutaraldehyde and $2 \%(\mathrm{w} / \mathrm{v})$ osmium tetroxide and embedded in a mixture of Spurr and acetone as described [23]. Thin sections were stained with $2 \%(\mathrm{w} / \mathrm{v})$ uranyl acetate and $2 \%(\mathrm{w} / \mathrm{v})$ lead citrate. Microscopic examination was carried out with a transmission electron microscope (Zeiss model Leo 906E with a CCD camera model 794). Gamma corrections were applied on pictures of very dark cells. For the visualization of whole cells, $3 \mu \mathrm{l}$ concentrated biomass was pipetted on EM grids (300 mesh, 
Stork Veco B.V, The Netherlands) and stained with $2 \%$ $(w / v)$ uranyl acetate.

4'-6'-diamidino-2-phenylindole stained cells were observed using a confocal laser scanning microscope LSM 800 equipped with an Airyscan (Zeiss, Jena, Germany) equipped with Plan-Apochromat $63 \times$ and $100 \times 1.4$ oil objectives. Light microscopic images were taken with an AxioScope epifluorescence microscope equipped with a $\mathrm{N}$ Achroplan $100 \times 1.25$ oil objective and an AxioCam ICc1 1.4-megapixel CCD camera (Zeiss, Jena, Germany).

\section{Fluorescence in situ hybridization}

Cells were pelleted at $10{ }^{\circ} \mathrm{C}$ and $13,000 \times g$ for $15 \mathrm{~min}$, washed with $0.9 \% \mathrm{NaCl}$ and fixed with $1: 1(\mathrm{v} / \mathrm{v}) 96 \%$ ethanol:PBS as described previously [25]. To increase permeability, cells were partly treated with Proteinase K (5 $\mathrm{mg} \mathrm{ml}^{-1}$ ) for $30 \mathrm{~min}$ at $37^{\circ} \mathrm{C}$ and Lysozyme $\left(1 \mathrm{mg} \mathrm{ml}^{-1}\right)$ for $15 \mathrm{~min}$ at room temperature. After dehydration in ethanol [26] cells were hybridized overnight in hybridization buffer containing $20 \%$ formamide with the FITClabeled universal bacterial probe EUB338 [27] and Cy3labeled probes specific for $\mathrm{Ca}$. Nitrocaldera or $\mathrm{Ca}$. Nitrotheca (Table S3), which were designed as described below. Up to three probes labeled with the same fluorescent dye were used simultaneously to detect $C a$. Nitrocaldera to increase signal intensity. Signal specificity was ensured by performing negative control hybridizations using the NON338 probe labeled in Cy3 [28]. Cells were embedded in Citifluor AF1 (Citifluor Ltd, London, UK) prior to microscopic observation at the LSM 800 (Zeiss).

\section{Chemical analyses}

Nitrite and nitrate were determined qualitatively with analytical test stripes (Merck KGaA, Germany) and quantitatively by HPLC via ion pair chromatography on a LiChrospher RP18 column $(125 \times 4 \mathrm{~mm}$; Merck) with UV detection in an automated system (Hitachi LaChrom Elite; VWR International GmbH, Darmstadt, Germany). Data acquisition and processing of nitrite and nitrate was performed with the integrated software EZChrom Elite 3.3.2. Ammonium was measured by an ortho-phthalaldehyde fluorescence assay $[29,30]$. To test for growth of NOB, nitrite was determined using the Griess-Ilosvay spot test [31].

\section{DNA extraction}

DNA for PCR and cloning was isolated using the Ultra-Clean DNA isolation kit (MO BIO Laboratories, Inc. Carlsbad, CA). For Illumina sequencing of culture A5 and A7 DNA was isolated via the RTP ${ }^{\circledR}$ DNA Mini Kit (Stratec molecular, Berlin, Germany) according to the manufacturer's instruction. DNA of culture A6 was obtained by phenol-chloroform extraction [32] using TE-sucrose buffer $(10 \mathrm{mM}$ Tris, $1 \mathrm{mM} \mathrm{Na} 2$ EDTA, $\mathrm{pH}$ $8.0,20 \%(\mathrm{w} / \mathrm{v})$ sucrose) in combination with freeze/thaw cycles ( $5 \times$ liquid nitrogen $/ 65^{\circ} \mathrm{C}$ for $5 \mathrm{~min}$ ). DNA of nitrite-oxidizing cultures was extracted with the PowerSoil ${ }^{\oplus}$ DNA isolation Kit (MO BIO Laboratories, Inc, Carlsbad, CA) according to the manufacturer's instructions with slight modifications: Before cell disruption via vortexing (step 5) Proteinase $\mathrm{K}\left(1 \mathrm{mg} \mathrm{ml}^{-1}\right)$, Lysozyme $\left(4 \mathrm{mg} \mathrm{ml}^{-1}\right)$ and RNase $\mathrm{A}\left(1 \mathrm{mg} \mathrm{ml}^{-1}\right)$ were added. The vortexing step was extended to $30 \mathrm{~min}$ at $37^{\circ} \mathrm{C}$.

\section{PCR}

To test for the presence of functional genes of bacterial and archaeal ammonia oxidation, the primer sets amoA-1f/ amoA-2r [33] and Arch-amoAf/Arch-amoAr [34] were used (Table S3). The presence of NOB belonging to Nitrospira was checked using the 16S rRNA gene-targeted primer set NxrB-169f/NxrB-638r [35] and of Nitrobacter with the $n x r A$ (encoding NXR subunit A)-targeted primers F1NorA/ R1NorA [36].

\section{Cloning and RFLP analyses}

Bacterial 16S rRNA genes were amplified by the bacterial primers 27F and 1492R [37] (Table S3). The PCR products were ligated into the pGEM-T vector cloning system (Promega, Mannheim, Germany) and transformed into chemically competent Escherichia coli JM109 as described in the manufacturer's instructions. For partial and near-complete sequencing of clone inserts, the plasmid primers SP6 and T7 were used to reamplify the insert. Restriction digestion was performed with the enzyme HapII. Unique RFLP patterns were identified after separation on a $3 \%(\mathrm{w} / \mathrm{v})$ agarose gel.

\section{(Semi) specific PCR for thermophilic NOB}

Fragments of the nxrA and $16 \mathrm{~S}$ rRNA genes of the three putative NOB were amplified using primer sets 1-6 (Tables S3 and S4), which were designed as described below. The following PCR program was used: initial denaturation at $95^{\circ} \mathrm{C}, 4 \mathrm{~min} ; 36 \times$ denaturation at $95^{\circ} \mathrm{C}$, $35 \mathrm{~s}$, annealing at $50^{\circ} \mathrm{C}, 45 \mathrm{~s}$ (primer set 1), elongation at $72{ }^{\circ} \mathrm{C}$, $45 \mathrm{~s}$; final elongation 8 min (primer sets $1,3,5$ ) or $12 \mathrm{~min}$ (primer sets $2,4,6$ ). The annealing temperatures for the other primer sets were $2: 50{ }^{\circ} \mathrm{C}, 3: 56^{\circ} \mathrm{C}, 4: 54^{\circ} \mathrm{C}, 5$ : $50{ }^{\circ} \mathrm{C}$, and $6: 45^{\circ} \mathrm{C}$.

\section{FISH probe and PCR primer design}

16S rRNA-targeted FISH probes and 16S rRNA genetargeted PCR primers were designed and evaluated using the "design probes" and "match probes" functions of ARB 
[38] and the nonredundant SILVA SSURef NR 99 database (releases 123 for probe design and 132 for probe evaluation) [39]. Probe sequences suggested by the probe design tool were checked and refined in the ARB sequence editor against manually curated alignments of all 16S rRNA gene sequences obtained in this study (see below) and a subset of Chloroflexi, including all highly similar sequences present in SILVA SSURef NR 99 release 123 and downloaded from the NCBI $n r$ database, and representative sequences from the more distantly related genera within the phylum. All oligonucleotides were designed to target one of the NOB candidates identified in the enrichment cultures by metagenomic sequencing (see below), and the most closely related sequences present in the dataset $(<94 \%$ sequence identity and monophyletic clustering in phylogenetic analyses). This rough level of sequence identity was chosen to ensure that the oligonucleotides designed here would also work in case of strain diversity among the enrichment cultures, and to allow future identification of also more distantly related NOB candidates in environmental samples. Probe and primer sensitivity and specificity were queried by matching the newly designed oligonucleotides against the complete SILVA SSURef NR 99 release 132 database allowing for 0 mismatches. Target and nontarget groups were defined based on monophyletic clustering in phylogenetic analyses (see below). All oligonucleotides were ensured to have $100 \%$ coverage of the target group, with no perfect-match non-target organism present in the database. Due to the high specificity of the newly designed FISH probes and the lack of pure cultures, no formamide series were performed to determine the optimal formamide concentrations during hybridization. Instead, all probes were employed at $20 \%$ formamide in the hybridization buffer (see above).

NxrA-targeted primers were designed manually in the ARB sequence editor. During primer design the main focus was on designing oligonucleotides that specifically distinguish between the NOB candidates present in the enrichments. In case this was not possible, group-specific forward were combined with semi-specific or highly specific reverse primers, which in combination allowed distinguishing between the NOB candidates.

\section{Amplicon sequencing}

For selected cultures, $10 \mathrm{ng}$ of genomic DNA were used to generate 16S rRNA gene amplicons. For cultures A5, A7, N2a and $\mathrm{N} 2 \mathrm{~b}$, amplicons were generated using the primers $341 \mathrm{~F}$ and 785R [40], followed by 454 pyrosequencing (300 bp, 3000 reads per sample). For all other cultures the primers $515 \mathrm{~F}$ and $806 \mathrm{R}$ [41] were used, with subsequent Illumina MiSeq sequencing $(2 \times 300 \mathrm{bp}, 20,000$ reads per sample). Operational taxonomic units (OTUs) were obtained from the preprocessed sequences by the qiime (v1.9.1) [42] de novo OTU picking workflow, summarized and visualized by the qiime summarize_taxa_through_plots.py script. Illumina sequences were processed, classified and summarized by MR DNA and their analysis pipeline (MR DNA, Shallowater, TX, USA) [43]. In short, sequences were joined and depleted of barcodes, followed by removal of sequences $<150 \mathrm{bp}$ or with ambiguous base calls. Sequences were denoised, OTUs generated and chimeras removed. OTUs were defined by clustering at 3\% divergence (97\% similarity). Final OTUs were taxonomically classified using BLASTn against a curated database derived from NCBI and RDPII (www.ncbi.nlm.nih. gov, http://rdp.cme.msu.edu). 16S rRNA gene amplicon data of the autoclaved culture N7 were obtained from Macrogen Inc. (Seoul, Rep. of Korea) with the bacterial primers $341 \mathrm{~F}$ and $805 \mathrm{R}$ on the Illumina platform $(2 \times 300 \mathrm{bp}, 100,000$ reads per sample) with subsequent OTU clustering as described above.

\section{Metagenomic sequencing}

DNA was fragmented using a Bioruptor (Diagenode, Seraing, Belgium). Sequencing libraries were generated using the NEBNext Ultra DNA Library Prep Kit for Illumina (New England Biolabs, Ipswich, USA) as per the manufacturer's recommendations. Size and quality of the libraries were visualized on a Bioanalyzer High Sensitivity Chip (Agilent Technologies, Santa Clara, USA). Diluted libraries were multiplex sequenced on the Illumina HiSeq 2500 instrument (Illumina, St. Diego, USA) by paired-end sequencing $(2 \times 100 \mathrm{bp})$.

\section{Metagenome assembly and binning}

Adapter removal, contaminant filtering, and quality trimming of Illumina HiSeq paired-end sequencing reads was performed using BBDUK (BBTOOLS version 37.76) [44]. Terminal base calls with a quality score below Q17 were trimmed. Processed reads with a mean quality score of $\geq \mathrm{Q} 20$ and length of $\geq 70 \mathrm{bp}$ were corrected for sequencing errors using BayesHammer [45]. Corrected reads for all samples were co-assembled using metaSPAdes v3.11.1 [46] with default settings. MetaSPAdes iteratively assembled the metagenome using kmer size of 21, 33, 55, 77, 99, and 127. Trimmed reads were mapped back to the metagenome separately for each sample using Burrows-Wheeler Aligner (BWA 0.7.17) [47], employing the "mem" algorithm. The sequence mapping files were handled and converted as needed using SAMtools 1.6 [48]. Metagenome binning was performed for contigs greater than $1500 \mathrm{bp}$ using five binning algorithms: BinSanity v0.2.6.1 [49], COCACOLA [50], CONCOCT [51], MaxBin 2.0 2.2.4 [52] and MetaBAT 2 2.12.1 [53]. The five bin sets were supplied to DAS Tool 1.0 
[54] for consensus binning to obtain the final optimized bins. The quality of the generated bins was assessed through singlecopy marker gene analysis using CheckM 1.0.7 [55]. Subsequently, the binned genomes where annotated using Prokka [56] against the NCBI RefSeq bacteria_protein database (release 86). Genes of interest where identified by BLAST searches [57] with selected reference sequences against the nucleotide and protein FASTA output files, or by manual inspection of the Prokka annotation. Functional pathway annotation was performed using the KEGG Automatic Annotation Server [58].

The absence of additional NXR genes in the unbinned fraction of the metagenome (unbinned contigs $\geq 1500 \mathrm{bp}$ from low-abundance organisms and contigs $<1500 \mathrm{bp}$ ) was verified by blasting representative $n x r A$ gene sequences against the complete metagenomic assembly using BLASTN and TBLASTX [57], and by mapping the corrected reads from all samples against the nxrA gene sequences identified in the binned genomes using BBMap (BBTOOLS version 37.76) [44] with the minimal alignment similarity cutoff set to 0.7 (parameters $\operatorname{minid}=0.70$ idfilter $=0.70$ ).

\section{Phylogenetic analyses}

16S rRNA gene sequences present in the genome bins were imported into ARB [38] in the Silva ARB database SSURef NR 99 release 123 [39], which was manually updated to contain all highly similar sequences from the NCBI $n r$ database. After automatic alignment (using the Fast align option within the ARB sequence editor) and subsequent manual refinement, a phylogenetic tree was constructed using the PhyML program [59] implemented in ARB with the GTR nucleotide substitution model, which was identified as best model available in ARB by ModelFinder (http:// iqtree.cibiv.univie.ac.at), and 100 nonparametric bootstraps. No conservation filter was applied and only alignment columns without information were filtered out, resulting in 1841 valid alignment positions.

For NxrA analyses, the protein sequences identified in the metagenomic bins were imported and aligned in ARB as described above. Subsequently, phylogenetic trees were calculated using MrBayes [60] (version 3.2.3, with the parameters aamodelpr $=$ mixed samplefreq $=500$ diagnfreq $=$ 5000 nruns $=2$ nchains $=4$ stoprule $=$ yes stopval $=0.01$ ), and using RAxML [61] (with the PROTMIX rate distribution and WAG amino acid substitution models and 100 rapid bootstrap runs) and PhyML (with the WAG amino acid substitution model and 100 non-parametric bootstraps) within ARB. The WAG substitution model was identified by MrBayes as the amino acid model with a posterior probability $=1.0$. For all NxrA tree calculations a $10 \%$ conservation filter was applied, resulting in 1198 valid alignment positions. Partial sequences were omitted from tree calculations.
The phylogenomic tree was reconstructed using UBCG [62]. First, all Chloroflexi (phylum) genomes available in the NCBI RefSeq Assembly database (accession date February 22,2018 ) were dereplicated using dREP [63] (with parameter settings -1 1500000 -comp 90 -con 10 -sa 0.95 -comW 2 -conW 1 -strW 1 -N50W 2 -sizeW 1 --checkM_method taxonomy_wf). Only the best genome assembly was retained for genomes $>95 \%$ identical. Subsequently, a set of 92 universal bacterial conserved phylogenetic marker proteins was automatically identified, aligned and concatenated in UBCG, followed by tree calculation using RAxML. UBCG also calculated separate trees for each marker protein; the support of each node by these single protein trees is indicated in the final concatenated tree.

\section{Environmental distribution analysis}

The integrated microbial next generation sequencing (IMNGS) platform [64] was used to analyze the environmental distribution of the organisms retrieved via metagenomic sequencing in this study. In short, the $16 \mathrm{~S}$ rRNA gene sequences extracted from the genome bins were used to query all prokaryotic $16 \mathrm{~S}$ rRNA amplicon datasets available in the NCBI Sequence Read Archive (SRA), which are integrated into IMNGS as samplespecific sequence databases and OTU-based profiles (accession data: June 16, 2019). This query was performed using 97 and $99 \% 16 \mathrm{~S}$ rRNA identity cutoffs. The resulting distribution patterns (expressed in sequence hit counts per amplicon dataset) were summarized to reflect the number of amplicon datasets from a common origin (e.g. hot springs) positive for the respective query sequence. The study origins for studies without automatic classification into one of the main categories within IMNGS were manually curated. Only amplicon datasets with $\geq 2$ query hits were counted as positive. Sequence count summaries were generated in Microsoft Excel using the PivotTable functionalities.

\section{Results}

\section{Enrichment of thermophilic NOB with ammonium}

Mineral media containing ammonium as sole energy source were used with the initial goal to enrich both, ammonia and nitrite oxidizers, simultaneously. Cultures were inoculated with biofilms and sediments from two hots springs in YNP (UWG009 and Diadem Spring; Fig. S1a-c, Tables S1 and S2). After 6 years of incubation at $65-70{ }^{\circ} \mathrm{C}$ and several transfers (Fig. S2) with repeated ammonia consumption (Fig. S3), we obtained a diverse bacterial community in cultures derived from both 


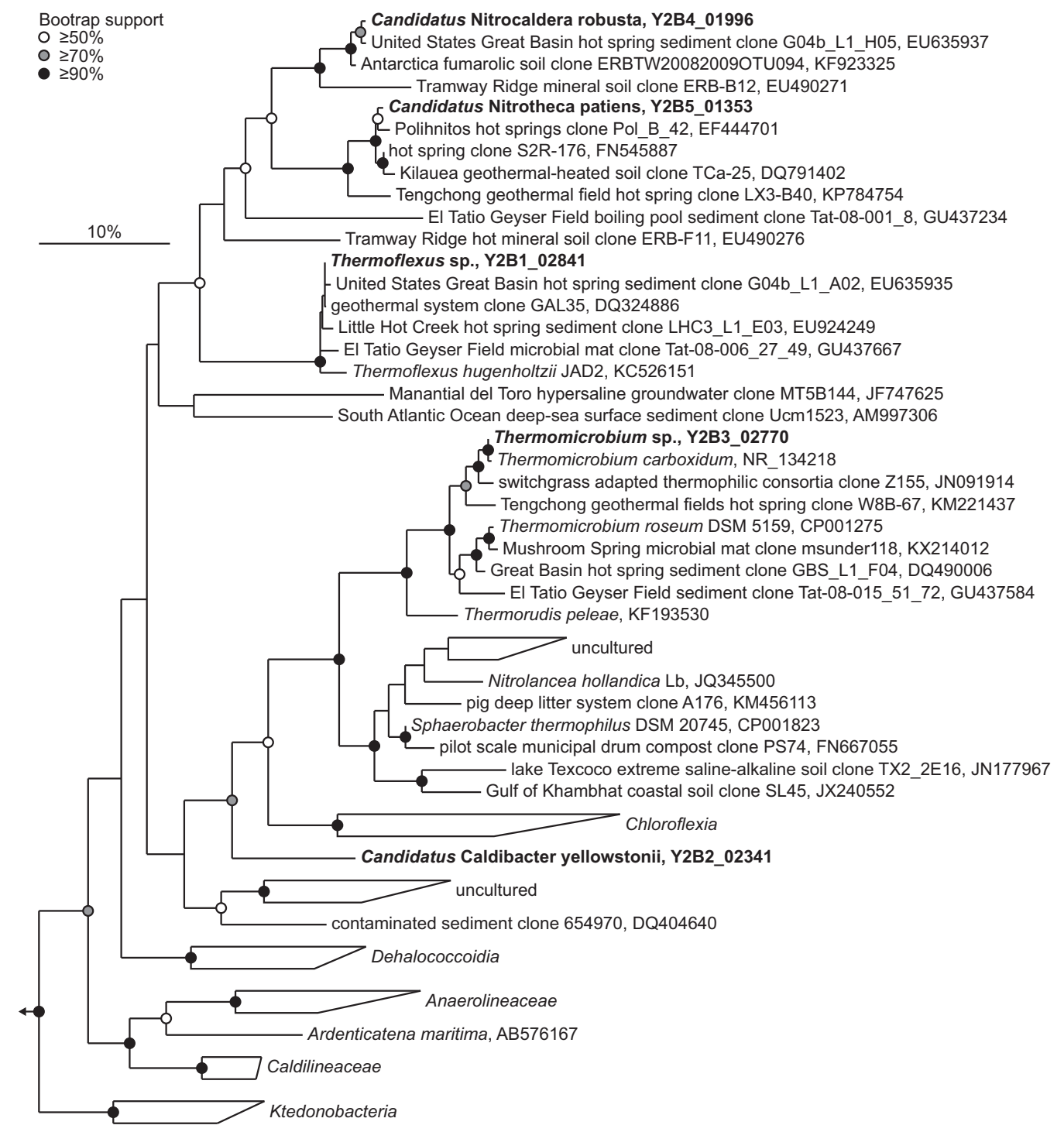

Fig. 1 16S rRNA gene-based phylogenetic analysis. Maximumlikelihood tree indicating the affiliation of the MAGs derived from the Yell 2 cultures within the phylum Chloroflexi. The tree was calculated without conservation filter, resulting in 1841 valid alignment positions. Sequences obtained in this study are shown in bold. The

springs, which mostly consisted of novel members of the phylum Chloroflexi (Fig. 1, Fig. S4, and Table S5). Known AOB were not found and no positive PCR reaction was achieved with the described primer sets for ammonia and nitrite-oxidizing microorganisms (Table S3). The thermophilic AOA Nitrosocaldus yellowstonii [11] was detected in primary enrichments, but disappeared during further transfers probably due to distinct cultivation conditions. High-throughput metagenomic sequencing revealed candidate genes for the key enzyme of nitrite oxidation (see below), but not for ammonia oxidation. This finding inspired us to initiate nitrite-oxidizing cultures from the ammonia-oxidizing enrichments (Fig. S2) to select for the novel NOB. open, gray and solid circles indicate $\geq 50 \%, \geq 70 \%$ and $\geq 90 \%$ bootstrap support, respectively. The arrow indicates the position of the outgroup, which consisted of a selection of nine Cyanobacteria. The scale bar corresponds to $10 \%$ estimated sequence divergence

\section{Mixotrophic growth of thermophilic NOB}

In the beginning of our cultivation attempts, nitrite oxidizers could not reproducibly be grown in standard mineral NOB media. In contrast, oxidation of nitrite to nitrate could be stimulated for unidentified reasons in the cultures that were transferred from AOB medium when ammonium and organic carbon (R2A, 1:5) were added to the mineral NOB medium. Before cells were transferred, the mineral AOB medium had been supplemented with nitrite and formate in order to stimulate growth of mixotrophic NOB [6]. After nitrification was induced, growth of the nitrite-oxidizing consortia was most successful when using a reduced amount of R2A (1:10). At $55^{\circ} \mathrm{C}$ and $60^{\circ} \mathrm{C}, 2.5 \mathrm{mM}$ nitrite 


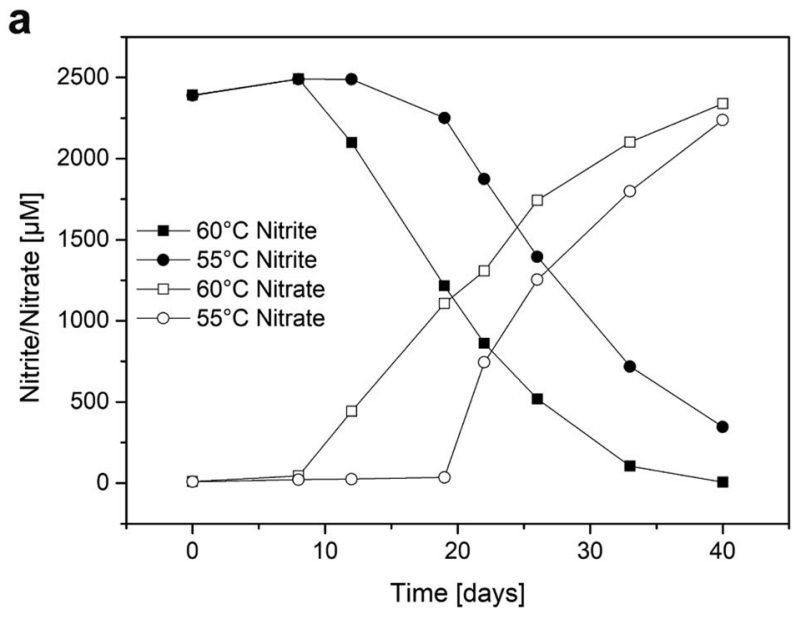

b

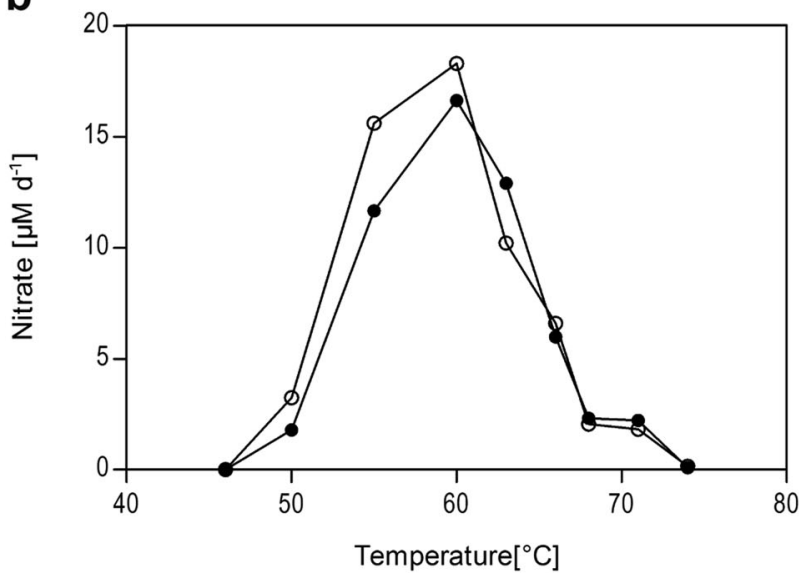

Fig. 2 Incubation experiments of Yell 2 cultures in mixotrophic NOB medium. a: Growth of cultures N2a $\left(55^{\circ} \mathrm{C}\right.$, circles) and $\mathrm{N} 2 \mathrm{~b}\left(60^{\circ} \mathrm{C}\right.$, squares) in diluted $\mathrm{R} 2 \mathrm{~A}(1: 10)$ that contained $2.5 \mathrm{mM}$ nitrite. b: Temperature optimum of culture $\mathrm{N} 6$ with $1 \mathrm{mM}$ nitrite and R2A (1:10). Activity was followed by measuring nitrate production, with the consumption rate evaluated between day 10 and 60 . The graph shows two biological replicates

was stoichiometrically oxidized to nitrate within 40 days (Fig. 2a), but no nitrite oxidation was observed with highly dilute R2A (1:20) or without R2A. Only little nitrite was consumed using elevated concentrations of organic matter (1:4 or 1:2), which lead to strongly increased growth of heterotrophic bacteria. Tests for optimal growth temperature revealed stoichiometric oxidation of $1 \mathrm{mM}$ nitrite to nitrate in the presence of diluted R2A (1:10) in the range of $50-71{ }^{\circ} \mathrm{C}$ with maximum activity at $60^{\circ} \mathrm{C}$ (Fig. 2b).

\section{Community analyses}

A high-throughput metagenomic sequencing approach included three cultures enriched in mineral $\mathrm{AOB}$ medium (A5, A6, and A7) and two cultures grown in mixotrophic NOB medium (N1 and N2a), five cultures which were derived from an initial enrichment inoculated with biofilm sampled in Spring UWG009 (Yell 2; Fig. S2). Co-assembly of the reads from these cultures resulted in a total of 523 contigs ( $\geq 1500 \mathrm{bp}$ ) with a total length of 16142227 nucleotides (Table S6). The use of a consensus binning approach allowed the retrieval of five distinct metagenomeassembled genomes (MAGs; Table S7). In correlation with 16S rRNA gene amplicon sequencing (Fig. S4) and cloning of the 16S rRNA genes (Table S5), most phylotypes belonged to distinct subgroups, which are (distantly) related to Thermoflexus hugenholtzii [65] or were identified as members of the genus Thermomicrobium [66, 67]. These thermophilic heterotrophs were originally isolated from sediment of Great Boiling Spring in Nevada (USA) [65], an alkaline hot spring in YNP [66] or volcanic soil in Hawaii [67].

The metagenomes of the nitrite- and ammonia-oxidizing cultures were mostly dominated by a single organism represented by bin_4 (Fig. S5). The 16S rRNA gene sequence of this bacterium, provisionally designated as Candidatus Nitrocaldera robusta, has $86 \%$ identity to Thermoflexus hugenholtzii (Fig. 1) and is $99 \%$ similar to environmental sequences from Antarctica fumarolic soil [68]. A Thermoflexus-like bacterium (bin_1; 99\% 16S rRNA gene identity to $T$. hugenholtzii) and a Thermomicrobium carboxidum-like bacterium (bin_3; 99\% 16S rRNA gene identity to $T$. carboxidum) were also regularly observed. Similar to bin_4, two additional MAGs (bin_5, named Candidatus Nitrotheca patiens and bin_2, named Candidatus Caldibacter yellowstonii) have no close taxonomically described relatives (Fig. S6). Their closest relatives are T. hugenholtzii (84\% 16S rRNA gene identity) and Sphaerobacter thermophilus (85\% 16S rRNA gene identity), respectively. Except for $\mathrm{Ca}$. Caldibacter, all phylotypes are highly similar to environmental $16 \mathrm{~S}$ rRNA gene sequences derived from geothermal settings (Fig. 1).

\section{Genomic identification of putative NOB}

Surprisingly, in three of the five MAGs genes encoding the nitrite oxidoreductase complex were detected. This molybdopterin-binding enzyme within the DMSO reductase type II family [69, 70] occurs in two forms: The Nitrobacter-type NXR, including the enzymes of Nitrococcus and Nitrolancea, is characterized by a cytoplasmic orientation of the enzyme complex, while the Nitrospira-type NXR, including the Nitrospina enzyme, is located in the periplasmic space [3, 5, 70]. The NxrA of Nitrobacter, Nitrococcus, and Nitrolancea is related to the alpha subunit of the respiratory membrane-bound nitrate reductase (NarG) of denitrifying bacteria [6,71], whereas those of Nitrospira and Nitrospina reveal a distinct phylogenetic affiliation with the NxrA of the anaerobic ammonium-oxidizing 


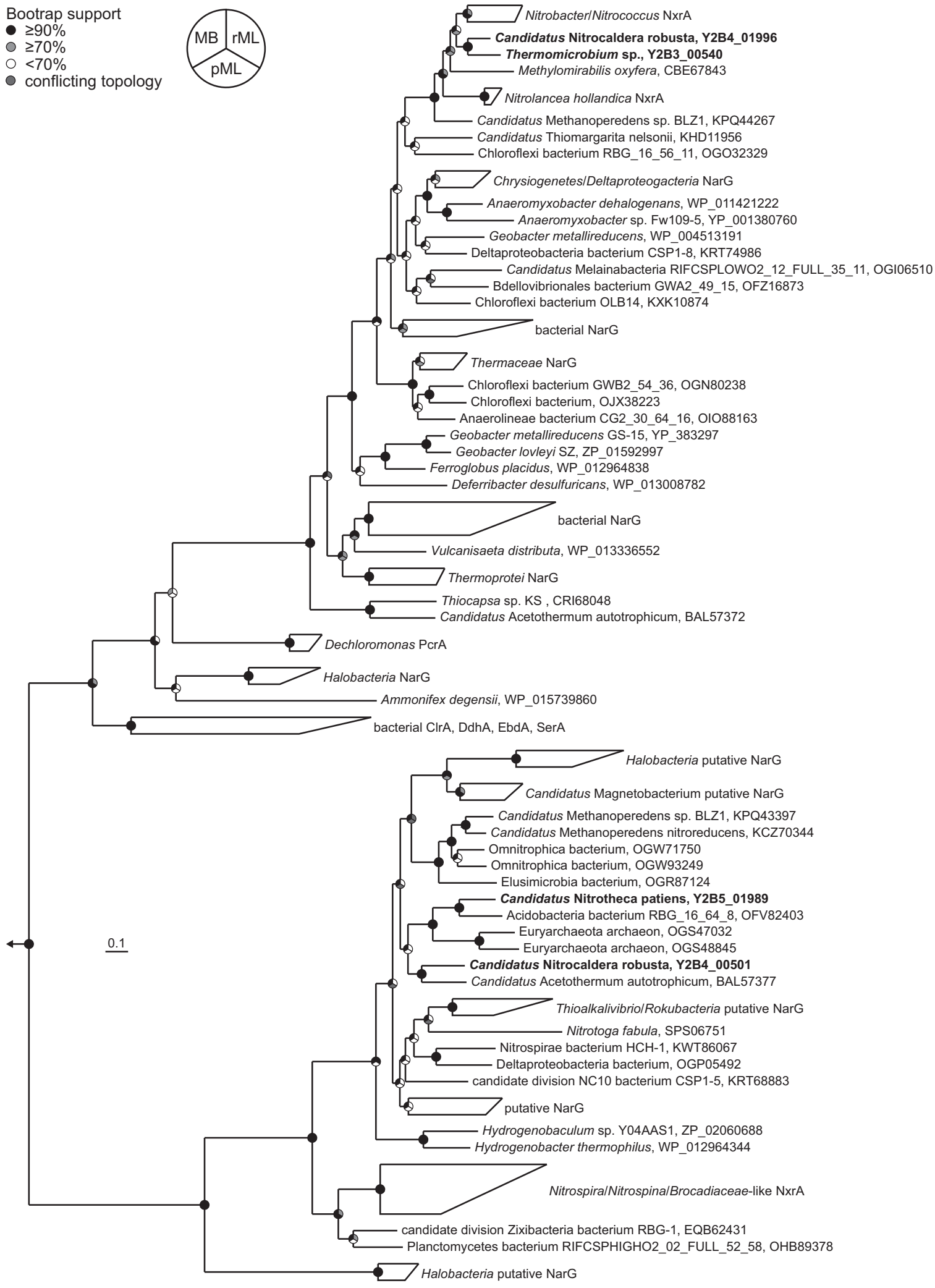

Brocadiaceae [70]. Recently, an additional distinct type of NXR was described in Nitrotoga, which is distantly related to the enzyme found in Nitrospira and also located in the periplasmic space [72]. In $\mathrm{Ca}$. Nitrocaldera two distinct
NXR candidates (Nitrobacter-type and Nitrotoga-type) were found (Fig. 3), with the protein sequence of the first showing $71 \%$ identity to the NxrAs of Nitrobacter and Nitrolancea hollandica. The two other MAGs contain only 
Fig. 3 Phylogenetic analysis of the NxrA protein. Bayesian inference tree indicating the affiliation of the NxrA-like sequences identified in the nitrite-oxidizing candidates present in the Yell 2 cultures. The tree was calculated using a $10 \%$ conservation filter, resulting in 1198 valid alignment positions. Analysis reached convergence after 3,475,000 generations with a final standard deviation of 0.009976. Statistical branch support obtained with different treeing algorithms is indicated by pie charts. MB, MrBayes; rML, RAxML (100 rapid bootstraps); pML, PhyML (100 nonparametric bootstraps). Conflicting tree topology between the Bayesian inference tree and one of the maximumlikelihood methods is indicated in red. The scale bar corresponds to $5 \%$ estimated sequence divergence. The arrow indicates the position of the outgroup, which consisted of six selected members of the MobB_4 sequence group of the type II DMSO reductase protein family

one variant of NXR. Ca. Nitrotheca encodes a Nitrotogatype, while Thermomicrobium sp. has a Nitrobacter-type NXR with $80 \%$ similarity to the enzyme of $C a$. Nitrocaldera (Table 1 and Fig. S7a).

In accordance with their affiliation with the Nitrotoga branch (Fig. 3), the second putative NxrA identified in $\mathrm{Ca}$. Nitrocaldera and the enzyme of $\mathrm{Ca}$. Nitrotheca are also predicted to have a periplasmic orientation. They cluster together with molybdopterin oxidoreductases from subsurface metagenomes [73], which are supposed to originate from autotrophic microorganisms in a thermophilic biofilm $\left(\sim 70^{\circ} \mathrm{C}\right)$ and represent extremophilic "dark matter" [74]. The Nitrotoga-like NxrA-like sequence of $\mathrm{Ca}$. Nitrocaldera is distantly related to a NXR/nitrate reductase of the deeply branching bacterium Candidatus Acetothermum autotrophicum [75]. BLAST analyses identified two partial sequences in the recently described Candidatus Caldiarchaeum subterraneum [76] as close relative of the NxrA-like protein of $\mathrm{Ca}$. Nitrotheca. These "Aigarchaeota" are a sister lineage to the AOA-containing Thaumarchaeota [20], but no nitrite-oxidizing potential has been reported to date.

Notably, $\mathrm{Ca}$. Nitrocaldera is the first putative NOB, which contains two different types of NxrA (Table 1 and Fig. 3). It is tempting to speculate that this organism possesses a flexible metabolism with regard to nitrite oxidation, indicating an adaptation to a wide range of nitrite concentrations. Alternatively, only one of the enzymes might be a real NXR, while the second type serves as dedicated nitrate reductase.

Although the Nitrotoga branch of NxrA contains many uncharacterized enzymes also from nitrate-reducing microorganisms, strong support for the nitrite-oxidizing nature of $\mathrm{Ca}$. Nitrotheca was found in an enrichment of Yell 3 (Table S2), which was grown at $55^{\circ} \mathrm{C}$ in mixotrophic NOB medium. This culture, consisting of $39 \% \mathrm{Ca}$. Nitrotheca, only 5\% $\mathrm{Ca}$. Nitrocaldera as second putative NOB and Thermorudis peleae as main heterotroph (Fig. S8a), accumulated $3.4 \mathrm{mM}$ nitrate after the consumption of the same amount of nitrite.

\section{Organization of the NXR operon}

In Nitrobacter, the membrane-associated NXR complex consists of the catalytic alpha (NxrA), an electrontransporting beta $(\mathrm{NxrB})$, and a membrane-integral, hemecontaining gamma $(\mathrm{NxrC})$ subunit. In addition, the NXR operon encodes a peptidyl-prolyl cis-trans isomerase (NxrX) and a TorD-like chaperone (NxrD) involved in insertion of the molybdopterin cofactor into NxrA. These genes are arranged in a nxrAXBDC order. The operons of the putative Nitrobacter-type NXR in $C a$. Nitrocaldera and Thermomicrobium sp. reveal a syntenic genetic organization as found in all other NOB containing this NXR type, with a highly conserved gene cluster furthermore containing a c-type cytochrome and a putative $\mathrm{C}_{4}$-dicarboxylate transporter (Fig. S7a).

Similarly, $C a$. Nitrotoga fabula contains genes for the three structural subunits of NXR (NxrABC), as well as a TorD-like chaperone NxrD. Unlike in the Nitrobacter-like enzyme complex, however, the Nitrotoga fabula NxrA contains a $\mathrm{N}$-terminal signal peptide for export into the periplasm via the twin-arginine translocation (TAT) system, and $\mathrm{NxrC}$ a signal peptide for translocation via the Sec pathway [72], as has also been described for Nitrospira defluvii [70]. Furthermore, the NXR gamma subunit does not contain any predicted transmembrane helices, indicating a soluble nature of the enzyme. Contrastingly, while the TAT signal peptide is conserved in the Nitrotoga-type NxrAs of $\mathrm{Ca}$. Nitrocaldera and $\mathrm{Ca}$. Nitrotheca NxrAs, the NxrC subunit of $\mathrm{Ca}$. Nitrocaldera contains one C-terminal transmembrane helix (amino acid positions 304-326) in addition to the $\mathrm{N}$-terminal signal peptide, and the $\mathrm{Ca}$. Nitrotheca $\mathrm{NxrC}$ a N-terminal transmembrane helix (amino acid positions 58-80) and no signal peptide. This indicates an anchoring of the NXR complex to the periplasmic face of the cytoplasmic membrane, which might be a necessary adaptation due to the apparent absence of outer membranes in many Chloroflexi [77]. A TorD-like chaperone could not be identified in these genomes (Fig. S7b).

\section{Genomic features of the novel NOB}

The total length of the obtained MAGs ranged from 2.4 to $3.6 \mathrm{Mb}$. The high $\mathrm{G}+\mathrm{C}$ content of the different genomes (65.2-69.9\%; Table S7) is in accordance with known thermophilic Chloroflexi species (64-69\%) [65]. The genomes of the two putative NOB $\mathrm{Ca}$. Nitrotheca and $\mathrm{Ca}$. Nitrocaldera are predicted to be near-complete and phylogenetic analyses of concatenated marker protein alignments revealed that these bacteria, along with the nonnitrifying $\mathrm{Ca}$. Caldibacter, form a separate phylogenetic lineage within the phylum Chloroflexi that is distinct from the described species (Fig. S6). Despite their close phylogenetic 
Table 1 Differentiation of NxrA-containing bacteria derived from Yell 2

\begin{tabular}{|c|c|c|c|c|c|}
\hline bin & Taxonomic affiliation & $\begin{array}{l}\text { NxrA } \\
\text { type }^{a}\end{array}$ & $\begin{array}{l}\text { Putative } \\
\text { morphotype (MT) }\end{array}$ & Rubisco $(r b c L)$ & $\begin{array}{l}\text { Detection in } \\
\text { nitrite-oxidizing } \\
\text { cultures }^{b}\end{array}$ \\
\hline 3 & Thermomicrobium sp. & Nb-like & MT3 & - & N1-N6 \\
\hline 4 & $C a$. Nitrocaldera robusta & $\begin{array}{l}\text { Nb-like } \\
\text { Nt-like }\end{array}$ & MT4 & $\begin{array}{l}78 \% \\
\text { Synechococcus }\end{array}$ & N1-N7 \\
\hline 5 & $\mathrm{Ca}$. Nitrotheca patiens & Nt-like & MT5 & - & $\mathrm{N} 1-\mathrm{N} 4, \mathrm{~N} 7$ \\
\hline
\end{tabular}

Summary of the results of metagenomic binning, electron microscopy and growth experiments. Only bacteria with a relative abundance of $>1 \%$ (amplicon sequencing) are shown. The main NOB candidate is printed in bold

N7: autotrophic growth with $\mathrm{NaHCO}_{3}$, inoculated with $\mathrm{N} 1$

N5-N6: cultures derived from autoclaved biomass

${ }^{\mathrm{a}} \mathrm{Nb}=$ nitrobacter, $\mathrm{Nt}=$ nitrotoga

${ }^{\mathrm{b}} \mathrm{N} 1-\mathrm{N} 6$ : mixotrophic growth

affiliation, the genome of our Thermoflexus strain shares an average nucleotide identity of $94.8 \%$ with Thermoflexus hugenholtzii, which indicates that they form two distinct species [78].

In $\mathrm{Ca}$. Nitrocaldera, the genetic inventory for $\mathrm{CO}_{2}$ fixation via the Calvin-Benson cycle indicated the potential for autotrophic growth predicted to be ribulose 1,5-bisphosphate carboxylase/oxygenase (Rubisco) with the large subunit (RbcL) having 78\% identity to the corresponding enzyme of Synechococcus. Rubisco is also present in Nitrobacter, Nitrococcus, Nitrolancea and Nitrotoga, but not in Nitrospira and Nitrospina, which use the reductive citric acid cycle for carbon fixation $[5,6,72,79]$. Thus, $C a$. Nitrocaldera is a potential chemolithoautotrophic organism, although amendment of organic carbon stimulated nitrite oxidation. It could not be clarified in this study if this effect is due to mixotrophic growth of the novel NOB as described for Nitrobacter [80] and most other NOB [81], or if organics mediate the chemical degradation of reactive oxygen species (ROS) against which many nitrifiers are sensitive [82]. Alternatively, organics might have an indirect positive effect by stimulating coexisting heterotrophs, which detoxify ROS or produce metabolites that support growth of the NOB.

In contrast to $\mathrm{Ca}$. Nitrocaldera, Rubisco genes were not identified in the draft genomes of $\mathrm{Ca}$. Nitrotheca or Thermomicrobium sp. Instead, $\mathrm{Ca}$. Nitrotheca encodes all enzymes of the reductive tricarboxylic acid (TCA) cycle and for pyruvate synthesis from acetyl-CoA, with the exception of the key enzyme ATP-citrate lyase. However, a reversibility of citrate synthase was demonstrated recently in Thermosulfidibacter takaii and Desulfurella acetivorans [83, 84], which might also explain the apparent autotrophic potential of $\mathrm{Ca}$. Nitrotheca. Although some reactions of the rTCA cycle are oxygen-sensitive, enzymatic adaptations allow its functioning in aerobic NOB like Nitrospira [70] as this probably also is the case in nitrite-oxidizing Chloroflexi.
As mentioned above, $C a$. Nitrocaldera is related to thermophilic bacteria inhabiting the oligotrophic subsurface of Tramway Ridge, Antarctica $\left(\mathrm{CO}_{2}\right.$ rich steam fumaroles) [68]. A possible reason for reduced autotrophic growth in our thermophilic cultures is a limitation of carbon dioxide, due to its low solubility at elevated temperatures. However, autotrophic growth was achieved when culture N1 was transferred into mineral NOB medium (culture N7) without $\mathrm{R} 2 \mathrm{~A}$, but supplemented with bicarbonate $(0.5 \mathrm{mM}$ $\mathrm{NaHCO}_{3}$; Fig. S2). Under these conditions especially the abundance of $\mathrm{Ca}$. Nitrotheca increased, along with Thermoflexus sp. (Fig. S4). In earlier ammonia-oxidizing cultures, amendment of $\mathrm{NaHCO}_{3}$ for $\mathrm{pH}$ adjustment might have fulfilled $\mathrm{CO}_{2}$ requirements of the thermophilic NOB, thus allowing lithoautotrophic growth.

Interestingly, all NOB candidates enriched in this study lacked genes for assimilatory nitrite reduction, indicating a dependency on ammonium for growth. The same observation has been made for Nitrolancea hollandica [6] and thus appears to be a general characteristic of nitrite-oxidizing Chloroflexi and will contribute to their apparent lack of growth in standard NOB medium [23]. A comparison of the main features of $\mathrm{Ca}$. Nitrocaldera, $\mathrm{Ca}$. Nitrotheca and Nitrolancea is shown in Table S8.

\section{Morphological diversity of thermophilic nitrite- oxidizing cultures}

Microscopic investigations of nitrite-oxidizing cultures of Yell 2 revealed a strong phenotypic heterogeneity (Fig. S9), but all cultures contained similar morphotypes as seen in the preliminary ammonia-oxidizing enrichments (Fig. S10). Two of the main morphotypes (MT1 and MT3) are very similar in cell shape and ultrastructure to the described species of Thermoflexus [65] and Thermomicrobium [66, 67], respectively, and MT2 resembles the coccoid cells of Sphaerobacter [85]. Notably, MT4 and MT5 have a unique morphology and ultrastructure (Fig. 4; see 
Fig. 4 Overview of the main morphotypes (MT) in NOB cultures derived from Yell 2 and their proposed identity based on correlation with literature data (MT1 and MT3) [65-67], as well as our own 16S rRNA gene amplicon data (Figs. 5, S4, S8, and S11), specific PCR

(Table S4) and FISH analyses (Figs. 5, S11-S13, and S18). For comparison, the pure culture of Thermomicrobium carboxidum KI3 (DSM 27067) was also investigated (not shown). Electron micrographs of a MT1 (Thermoflexus sp.), b MT2 (Ca. Caldibacter yellowstonii), c MT3 (Thermomicrobium sp.), d MT4 ( $\mathrm{Ca}$. Nitrocaldera robusta; see also Fig. 5 and S11), e: MT5 (Ca. Nitrotheca patiens; see also Figs. S12 and S13). All pictures were derived from culture $\mathrm{N} 2 \mathrm{a}$ except MT2, which was observed in a follow-up culture of $\mathrm{N} 2 \mathrm{a}$ at $55^{\circ} \mathrm{C}$. The arrow indicates a membrane-derived structure interpreted to be a lateral vesicle of unknown function
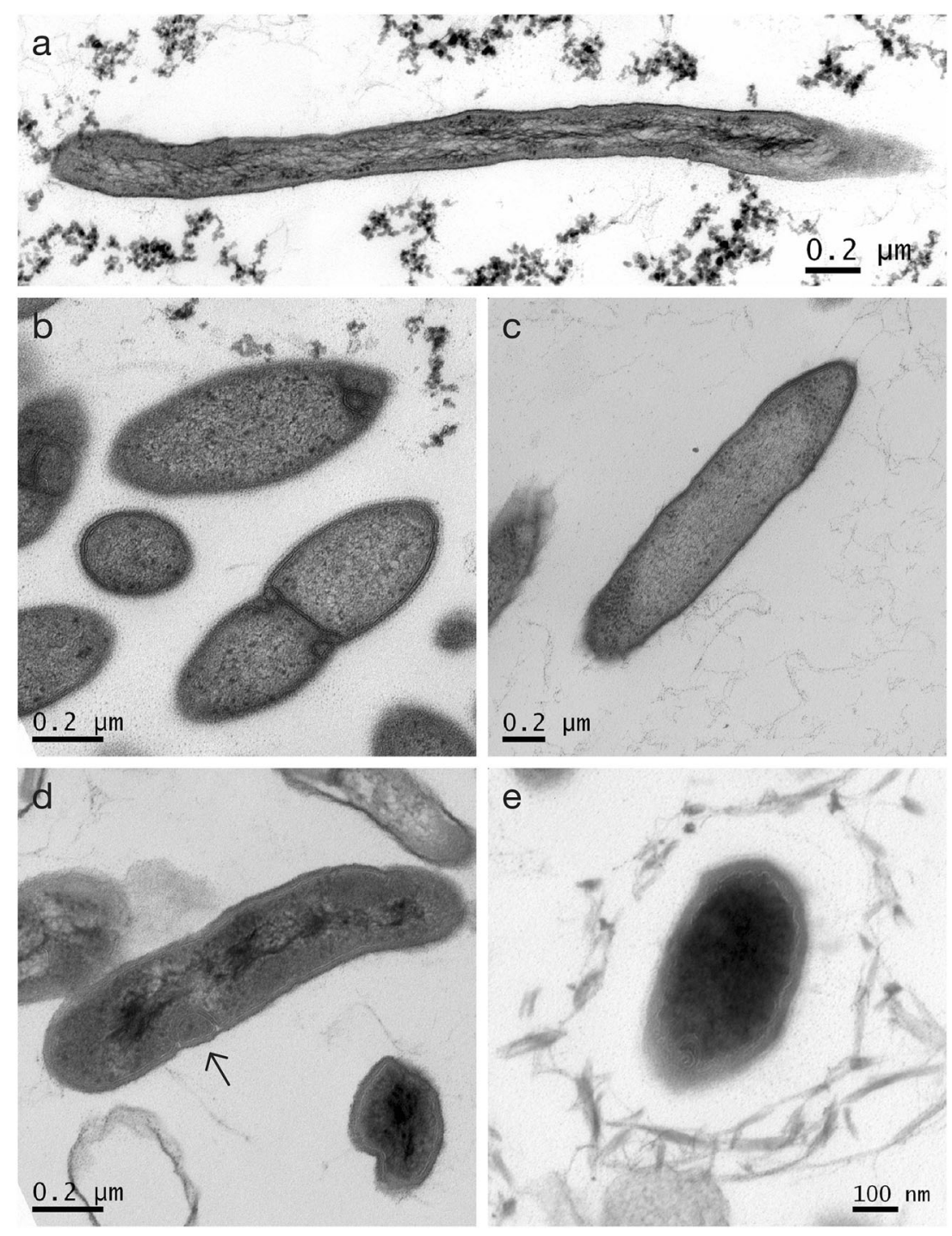

supplementary text). They remain the best NOB candidates and their occurrence in nitrite-oxidizing cultures obtained from Yell 2 and Yell 3 was proven by amplicon sequencing and FISH. Probes targeting $\mathrm{Ca}$. Nitrocaldera labeled pleomorphic short rods (Fig. 5a), which gave a strong fluorescent signal at the cell poles (Fig. S11b). Ca. Nitrotheca specific probes labeled ovoid cells and compact short rods in nitrite-oxidizing cultures derived from Yell 2 and Yell 3 (Fig. S12 and S13a).

\section{Putative NOB are heat resistant}

During our cultivation approach, the first active nitriteoxidizing culture N1 was obtained after supplementing the ammonia-oxidizing culture A6 with an aliquot of cell suspension from an ammonia-oxidizing culture inoculated in 2007, which had been "sterilized" by autoclaving (Fig. S2; supplementary text). The goal of this procedure was to possibly add missing trace elements present in the seeding material. Whereas most cells in active cultures containing $\mathrm{Ca}$. Nitrocaldera revealed pleomorphic rods (Fig. S14a), small light-refracting granules were observed in aging cultures (Fig. S14b). This finding indicated the presence of heat-resistant cells and the autoclaving process was repeated with culture $\mathrm{N} 3\left(121^{\circ} \mathrm{C}, 20 \mathrm{~min}\right)$. The autoclaved material was spread on R2A agarose plates (containing nitrite and ammonium) and inoculation of mixotrophic NOB medium with cells from a brownish colony resulted in culture N5. Primarily, $\mathrm{Ca}$. Nitrocaldera was identified by the universal 16S rRNA gene primer set 27F/1492R and by (semi) specific PCR, but after 106 days positive signals for Thermomicrobium sp. were also obtained (Table S4). In subsequent enrichments, they coexisted in mixotrophic NOB medium (cultures N6a $+\mathrm{b}$ ) and were furthermore accompanied by Geobacillus (Fig. S4). Whereas autoclaving of NOB cultures supplemented with R2A containing glucose selected 


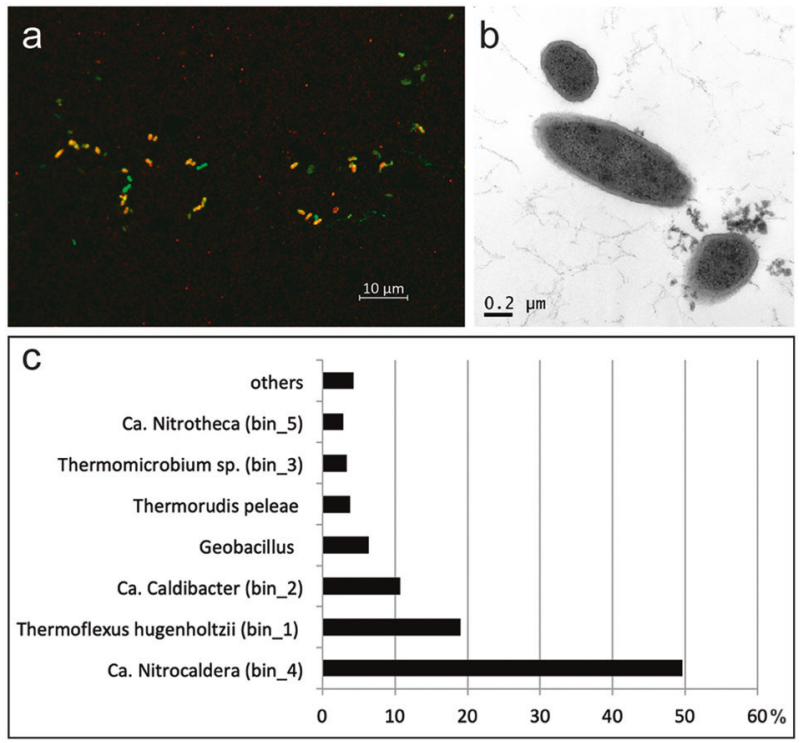

Fig. 5 Identification of $\mathrm{Ca}$. Nitrocaldera in a nitrite-oxidizing culture inoculated with $\mathrm{N} 1$ and grown at $60^{\circ} \mathrm{C}$ in mixotrophic $\mathrm{NOB}$ medium ( $0.3 \mathrm{mM}$ nitrite, $0.5 \mathrm{mM}$ ammonium) with $10 \%$ HWB. a FISH analysis with a combination of probes Ncal_1281 + Ncal_825 (Cy3, in red) and EUB338 (FITC, in green), cells labeled with both dyes appear yellow, b Electron micrograph of typical Gram-positive rods constituting approximately $80 \%$ of the embedded cells. c Relative abundance of bacterial species-level OTU obtained by 16S rRNA gene amplicon sequencing

for the enrichment of Geobacillus, heat treatment of the autotrophic culture $\mathrm{N} 7$ proved to be a more appropriate strategy to enrich for the putative NOB. Again, cells of $C a$. Nitrocaldera survived, whereas the relative abundance of $\mathrm{Ca}$. Nitrotheca was reduced (Fig. S11a).

Consequently, cells of $\mathrm{Ca}$. Nitrocaldera persisted heat treatment $\left(121^{\circ} \mathrm{C}\right)$ at 1 bar repeatedly, but the mechanism of heat-resistance requires further clarification. One strategy might be the formation of exospores, which has already been observed in the related Chloroflexi Ktedonobacter, Thermosporothrix and Thermogemmatispora [86]. Another survival strategy is the differentiation of vegetative cells into resistant resting structures which are produced under harsh conditions by many non-spore formers. Modified cells of circular shape and reduced size have been shown to be able to persist extreme conditions like wet heat or desiccation [87, 88]. Interestingly, after dormancy with low metabolic activity, $\mathrm{Ca}$. Nitrocaldera depends on the supply of small amounts of organic matter for proliferation and subsequent nitrite oxidation.

\section{Ca. Nitrocaldera appears as main NOB}

The molecular, metagenomic, and microscopic results imply that $\mathrm{Ca}$. Nitrocaldera represents the dominant NOB candidate in nitrifying cultures containing ammonium and/ or nitrite as energy source (Figs. 5, S4, S5, and Table 1). The abundance of $\mathrm{Ca}$. Nitrotheca declined over time, whereas $\mathrm{Ca}$. Nitrocaldera was maintained during continuous growth in mixotrophic NOB medium (Table S4). Cells retained their nitrite-oxidizing activity with stoichiometric nitrate formation after several transfers (Fig. 2a) and could be enriched to nearly $50 \%$ purity when the composition of the mixotrophic medium was modified (Fig. 5). $\mathrm{Ca}$. Nitrocaldera could also be enriched from the second investigated hot spring (Diadem Spring, samples Yell 4 and 5; Table S5) and is supposed to be widely distributed in this thermophilic area.

\section{Environmental distribution of novel chloroflexi}

All 16S rRNA amplicon datasets available at NCBI were subsequently screened for the presence of the five novel Chloroflexi species identified by metagenomic sequencing in the ammonia- and nitrite-oxidizing cultures. As expected, sequences closely related to the organisms identified in this study were detected in a range of datasets derived from hot springs and fumarolic sediments (Fig. S15). Also soil and the rhizosphere apparently frequently harbor especially $C a$. Nitrotheca and Thermomicrobium-like organisms, and Thermomicrobium furthermore is encountered in many composting systems and activated sludge. Interestingly, this analysis additionally indicated the gut of organisms as diverse as catarina scallops (Argopecten ventricosus), green sea urchins (Lytechinus variegatus), and the house mouse (Mus musculus) as a major habitat of both $\mathrm{Ca}$. Nitrocaldera and $\mathrm{Ca}$. Nitrotheca, but also of Thermoflexus and $\mathrm{Ca}$. Caldibacter, indicating their adaptation to a surprisingly diverse range of ecosystems.

\section{Discussion}

The phylum Chloroflexi is one of the main bacterial groups found in hot springs worldwide [89] and it also is abundant in various natural and constructed habitats [90]. Our knowledge of the diversity of Chloroflexi has undergone enormous expansion in the last 15 years, revealing diverse physiological features (e.g. photosynthesis, organoheterotrophy or lithoautotrophy) with at least seven subclasses containing both mesophilic and thermophilic representatives [65].

In this study, two putative nitrite-oxidizing novel Chloroflexi ( $\mathrm{Ca}$. Nitrocaldera and $\mathrm{Ca}$. Nitrotheca) were found in nitrifying cultures derived from hot springs in YNP. In contrast, a third NXR-containing bacterium is nearly identical to Thermomicrobium carboxidum [67], which however may have distinct requirements to consume nitrite compared to $\mathrm{Ca}$. Nitrocaldera. Alternatively, the 
NXR-like enzyme might function as canonical nitrate reductase in Thermomicrobium sp.

The community of thermophilic NOB and associated heterotrophic bacteria investigated here represents a dynamic system, which is able to adapt to varying culture conditions. They revealed morphological (Figs. S16-S19) as well as physiological flexibility with a proposed potential for autotrophic, mixotrophic and heterotrophic growth. Nevertheless, the complex community consisting of five different Chloroflexi was a very stable consortium adapted to limiting concentrations of nutrients and oxygen, resembling the natural environmental conditions. This community could be maintained for 12 years in mineral AOB or NOB medium.

Both, the putative nitrite oxidizers and the accompanying bacteria belong to the phylum Chloroflexi. Thermoflexus sp., Thermomicrobium sp. and $\mathrm{Ca}$. Caldibacter are assumed to be heterotrophic, but also exist under lithoautotrophic conditions like in initial ammonia-oxidizing cultures. In contrast, the putative NOB $\mathrm{Ca}$. Nitrocaldera and $\mathrm{Ca}$. Nitrotheca appear to have the ability for autotrophic growth, but prefer an ancient chemolithomixotrophic life style [75]. Their abundance increased in incubation strategies similar to culture N1 (Table S4), supplemented once with organic matter and subsequently only supplied with nitrite and ammonium. $\mathrm{Ca}$. Nitrocaldera represents the first heat-resistant nitrite oxidizer, a survival strategy enabling existence in hot springs and volcanic soils. The growth temperature optimum and maximum of $60{ }^{\circ} \mathrm{C}$ and $71{ }^{\circ} \mathrm{C}$, respectively, are clearly above those of the thermophilic members of Nitrospira (growth temperature limit $60-65^{\circ} \mathrm{C}$ ) $[15,16]$. A putative thermophilic NOB with $n x r A B$ genes within the Nitrobacter/ Nitrolancea cluster was already enriched in co-culture with an ammonia-oxidizing Thaumarchaeon from a hot spring in Iceland [13], which supports our finding that the phylum Chloroflexi contains several novel NOB.

Filamentous Chloroflexi provide a matrix in which other cells can become stably embedded [91] and occurrence in multicellular aggregates cause enormous difficulties in isolation procedures. Another reason for the failure of isolation of $\mathrm{Ca}$. Nitrocaldera might be its dependency on a (facultatively) heterotrophic bacterium and complex interactions in the nitrifying consortia are hypothesized. Nitrite was only oxidized in co-culture with Thermomicrobium sp. and/or Thermoflexus sp., which were consistently detected in the nitrifying enrichments since 2007. In some cultures, putative NOB were also accompanied by spore forming members of the genus Geobacillus, which sporadically proliferated when R2A was added and are known to stimulate thermophilic bacteria by $\mathrm{CO}_{2}$ supply [92]. So far, no nitrite-oxidizing pure culture could be obtained.

Dependency on other members of the natural community is a well-known finding in hot springs [91] and might be due to growth on low-molecular weight organic compounds or other metabolites excreted by others [93]. Bacterial interactions are in the focus of new cultivation concepts [94] and development of new media and isolation strategies are required. Nevertheless, by the design of novel (semi) specific primer sets, it will now be possible to detect these (and other) new NOB in environmental samples, e.g. from volcanic systems. These reference cultures are of high scientific value to study the diversity and adaptations to low nutrient availability and extreme conditions as well as evolutionary processes, as hot spring conditions are typical to the early environment of the planet earth [95].

\section{Taxonomic consideration of "Candidatus Nitrocaldera robusta" gen. nov. sp. nov}

L. n. nitrum: nitrate, N.L. fem. n. caldera: from the Spanish n. caldera, cauldron; designating a volcanic crater. L. fem. adj. robusta: strong. A robust (autoclaving-resistant) nitrateforming bacterium from a volcanic caldera. Phylogenetically affiliated with the phylum Chloroflexi.

Pleomorphic rods $0.3 \times 0.5-3 \mu \mathrm{m}$ with an electron-dense cytoplasm, Gram-positive. Lateral vesicle extrusion, produces aggregates, formation of dwarf cells, which are connected by fibers. Aerobic, facultative chemolithoautotroph that oxidize nitrite $(0.3-5 \mathrm{mM})$ to nitrate and use carbon dioxide as carbon source. Growth is stimulated by organic compounds, requires ammonium supplements. Obligately thermophilic with a temperature range of $50-71{ }^{\circ} \mathrm{C}$ and an optimum of $60{ }^{\circ} \mathrm{C}$; Heat resistant, survives autoclaving at $121^{\circ} \mathrm{C}$. Prefers neutral $\mathrm{pH}$, but tolerates slightly acidic conditions (pH 5.5). The DNA G $+\mathrm{C}$ content is $67 \mathrm{~mol} \%$.

\section{Taxonomic consideration of "Candidatus Nitrotheca patiens" gen. nov. sp. nov}

L. n. nitrum: nitrate, L.n. theca: capsule, L. adj. patiens: persistent. A perennial, spiny EPS covered putative nitriteoxidizing bacterium within the phylum Chloroflexi.

Ovoid cells $(0.2 \times 0.3 \mu \mathrm{m})$ extending to rods (up to 1.5 $\mu \mathrm{m})$ with an electron-dense cytoplasm, Gram-positive. Covered by a regular protein layer and crystal-like extracellular polymeric substances. Aerobic, obligate chemolithoautotroph that oxidizes nitrite to nitrate, requires ammonium supplementation. Obligately thermophilic, grows at $55-70{ }^{\circ} \mathrm{C}$. The DNA $\mathrm{G}+\mathrm{C}$ content is $69 \mathrm{~mol} \%$.

\section{Taxonomic consideration of "Candidatus Caldibacter yellowstonii" gen. nov. sp. nov}

L. adj. caldus: hot, N. L. masc. n. bacter: a rod, N. L. masc. adj. yellowstonii: pertaining to the habitat of the type strain, the YNP. Phylogenetically affiliated with the phylum Chloroflexi. 
A thermophilic bacterium that oxidizes organic substances at neutral $\mathrm{pH}$ and temperatures between $55-70{ }^{\circ} \mathrm{C}$. The DNA $\mathrm{G}+\mathrm{C}$ content is $70 \mathrm{~mol} \%$.

\section{Data availability}

Metagenomic and 16S rRNA gene amplicon sequence data are available in the European Nucleotide Archive (ENA) under accession number PRJEB28556. Requests for bacterial enrichment cultures are subject to the "General Permit Conditions" and cannot be shared by the authors without permission from U.S. National Park Service.

Acknowledgements The authors thank the National Park Service for permission to perform research in Yellowstone National Park (Permit YELL-2007-SCI-5698). Elke Woelken is acknowledged for excellent technical help in electron microscopy and Yvonne Bedarf and Christina Bietz for initial cultivation. We also thank Lia Burkhardt and Kerstin Reumann for sequencing assistance and we are grateful to Ilias Lagkouvardos and Antonios Kioukis for kindly enabling our analyses on the IMNGS platform.

Funding This work was funded by the Deutsche Forschungsgemeinschaft (DFG, German Research Foundation grant SP $667 / 7-1+2)$ and the Netherlands Organization for Scientific Research (Grants 863.14.019, 016.Vidi.189.050 and SIAM Gravitation Grant 024.002.002).

Author contribution EB and JS performed sampling at YNP, ES, JH, SL designed research, ES, KW, JH, DI performed research, JH, MA, MS, JF, SL analyzed data, and ES, JH and SL wrote the paper. All authors read and agreed on the final paper.

\section{Compliance with ethical standards}

Conflict of interest The authors declare that they have no conflict of interest.

Publisher's note Springer Nature remains neutral with regard to jurisdictional claims in published maps and institutional affiliations.

\section{References}

1. Alawi M, Lipski A, Sanders T, Eva-Maria-Pfeiffer, Spieck E. Cultivation of a novel cold-adapted nitrite oxidizing betaproteobacterium from the Siberian Arctic. ISME J. 2007;1:256-64.

2. Reigstad LJ, Richter A, Daims H, Urich T, Schwark L, Schleper C. Nitrification in terrestrial hot springs of Iceland and Kamchatka. FEMS Microbiol Ecol. 2008;64:167-74.

3. Spieck E, Bock E. The lithoautotrophic nitrite-oxidizing bacteria. In: Garrity G, Brenner DJ, Krieg NR, Staley JT, editors. Bergey's manual of systematic bacteriology. Berlin/Heidelberg, Germany: Springer-Verlag; 2005. p. 149-53.

4. Ehrich S, Behrens D, Lebedeva E, Ludwig W, Bock E. A new obligately chemolithoautotrophic, nitrite-oxidizing bacterium, Nitrospira moscoviensis sp. nov. and its phylogenetic relationship. Arch Microbiol. 1995;164:16-23.

5. Lücker S, Nowka B, Rattei T, Spieck E, Daims H. The genome of Nitrospina gracilis illuminates the metabolism and evolution of the major marine nitrite oxidizer. Front Microbiol. 2013;4:3-19.
6. Sorokin DY, Lücker S, Vejmelkova D, Kostrikina NA, Kleerebezem R, WIC Rijpstra, et al. Nitrification expanded: discovery, physiology and genomics of a nitrite-oxidizing bacterium from the phylum Chloroflexi. ISME J. 2012;6:2245-56.

7. Hedlund B, Thomas S, Dodsworth J, Zhang C. Life in hightemperature environments. In: Yates M, Nakatsu C, Miller R, Pillai S, editors. Manual of environmental microbiology, 4th ed. Washington, DC., USA: ASM Press; 2016. p. 4.3.4-1-4.3.4-15. https://doi.org/10.1128/9781555818821.ch4.3.4.

8. Dodsworth J, Hungate B, Hedlund BP. Ammonia oxidation, denitrification and dissimilatory nitrate reduction to ammonium in two US Great Basin hot springs with abundant ammoniaoxidizing archaea. Environ Microbiol. 2011;13:2371-86.

9. Inskeep WP, Ackerman GG, Taylor WP, Kozubal M, Korf S, Macur RE. On the energetics of chemolithotropy in nonequilibrium systems: case studies of geothermal springs in Yellowstone National Park. Geobiology. 2005;3:297-317.

10. Dodsworth JA, McDonald AI, Hedlund BP. Calculation of total free energy yield as an alternative approach for predicting the importance of potential chemolithotrophic reactions in geothermal springs. FEMS Microbiol Ecol. 2012;81:446-54.

11. de la Torre JR, Walker CB, Ingalls AE, Könneke M, Stahl DA. Cultivation of a thermophilic ammonia oxidizing archaeon synthesizing crenarchaeol. Environ Microbiol. 2008;10:810-8.

12. Abby SS, Melcher M, Kerou M, Krupovic M, Stieglmeier M, Rossel C, et al. Candidatus Nitrosocaldus cavascurensis, an ammonia oxidizing, extremely thermophilic archaeon with a highly mobile genome. Front Microbiol. 2018;9:1-19.

13. Daebeler A, Herbold CW, Vierheilig J, Sedlacek CJ, Pjevac P, Albertsen M, et al. Cultivation and genomic analysis of 'Candidatus Nitrosocaldus islandicus,' an obligately thermophilic, ammonia-oxidizing thaumarchaeon from a hot spring biofilm in Graendalur valley, Iceland. Front Microbiol. 2018;9:1-16.

14. Becraft ED, Dodsworth JA, Murugapiran SK, Ohlsson JI, Briggs BR, Kanbar J, et al. Single-cell-genomics-facilitated read binning of candidate phylum EM19 genomes from geothermal spring metagenomes. Appl Environ Microbiol. 2016;82:992-1003.

15. Lebedeva EV, Off S, Zumbrägel S, Kruse M, Shagzhina A, Lücker S, et al. Isolation and characterization of a moderately thermophilic nitrite-oxidizing bacterium from a geothermal spring. FEMS Microbiol Ecol. 2011;75:195-204.

16. Edwards TA, Calica NA, Huang DA, Manoharan N, Hou W, Huang L, et al. Cultivation and characterization of thermophilic Nitrospira species from geothermal springs in the US Great Basin, China, and Armenia. FEMS Microbiol Ecol. 2013;85:283-92.

17. Kits KD, Sedlacek CJ, Lebedeva EV, Han P, Bulaev A, Pjevac P, et al. Kinetic analysis of a complete nitrifier reveals an oligotrophic lifestyle. Nature. 2017;549:269-72.

18. Hugenholtz P, Pitulle C, Hershberger KL, Pace NR. Novel division level bacterial diversity in a Yellowstone hot spring. J Bacteriol. 1998;180:366-76.

19. Meyer-Dombard DR, Shock EL, Amend JP. Archaeal and bacterial communities in geochemically diverse hot springs of Yellowstone National Park, USA. Geobiology. 2005;3:211-27.

20. Hedlund BP, Murugapiran SK, Alba TW, Levy A, Dodsworth JA, Goertz GB, et al. Uncultivated thermophiles: current status and spotlight on 'Aigarchaeota'. Curr Opin Microbiol. 2015;25:136-45.

21. Kato S, Sakai S, Hirai M, Tasumi E, Nishizawa M, Suzuki K, et al. Long-term cultivation and metagenomics reveal ecophysiology of previously uncultivated Thermophiles involved in biogeochemical nitrogen cycle. Microbes Environ. 2018:33:107-10.

22. Krümmel A, Harms H. Effect of organic matter on growth and cell yield of ammonia-oxidizing bacteria. Arch Microbiol. 1982;133:50-54. 
23. Spieck E, Lipski A. Cultivation, growth physiology, and chemotaxonomy of nitrite-oxidizing bacteria. In: Klotz MG, editor. Methods in enzymology. 1st ed. Oxford, UK: Academic Press/ Elsevier Inc.; 2011. p. 109-30.

24. Widdel F, Bak F. Gram-negative mesophilic sulfate-reducing bacteria. The Prokaryotes. New York, NY, USA: Springer New York; 1992. p. 3352-78.

25. Amann R, Ludwig W, Schleifer K. Phylogenetic identification and in situ detection of individual microbial cells without cultivation. Microbiol Rev. 1995;59:143-69.

26. Manz W, Amann R, Ludwig W, Wagner M, Schleifer K-H. Phylogenetic oligodeoxynucleotide probes for the major subclasses of Proteobacteria: problems and solutions. Syst Appl Microbiol. 1992;15:593-600.

27. Amann RI, Binder BJ, Olson RJ, Chisholm SW, Devereux $\mathrm{R}$, Stahl DA. Combination of 16S rRNA-targeted oligonucleotide probes with flow cytometry for analyzing mixed microbial populations. Appl Environ Microbiol. 1990; 56:1919-25.

28. Wallner G, Amann R, Beisker W. Optimizing fluorescent in situ hybridization with rRNA-targeted oligonucleotide probes for flow cytometric identification of microorganisms. Cytometry. 1993;14:136-43.

29. Taylor S, Ninjoor V, Dowd DM, Tappel AL. Cathepsin B2 measurement by sensitive fluorometric ammonia analysis. Anal Biochem. 1974;60:153-62.

30. Corbin JL. Liquid chromatographic-fluorescence determination of ammonia from nitrogenase reactions: A 2 min assay. Appl Environ Microbiol. 1984;47:1027-30.

31. Schmidt EL, Belser LW. Autotrophic nitrifying bacteria. In: Weaver RW, Angle JS, Bottomley PJ, editors. Methods of soil analysis. Part 2-microbiological and biochemical properties. Madison, WI, USA: Soil Science Society of America; 1994. p. 159-77.

32. Sambrook J, Green MR, editors. Extracting DNA from gramnegative bacteria. Molecular cloning: a laboratory manual, 4th ed. New York, NY: Cold Spring Harbor Laboratory Press; 2012 p. 19-20.

33. Rotthauwe J, Witzel K, Liesack W. The ammonia monooxygenase structural gene amoA as a functional marker: molecular fine-scale analysis of natural ammonia-oxidizing populations. Appl Environ Microbiol. 1997;63:4704-12.

34. Francis CA, Roberts KJ, Beman JM, Santoro AE, Oakley BB. Ubiquity and diversity of ammonia-oxidizing archaea in water columns and sediments of the ocean. Proc Natl Acad Sci USA. 2005;102:14683-8.

35. Pester M, Maixner F, Berry D, Rattei T, Koch H, Lücker S, et al. $\mathrm{NxrB}$ encoding the beta subunit of nitrite oxidoreductase as functional and phylogenetic marker for nitrite-oxidizing Nitrospira. Environ Microbiol. 2014;16:3055-71.

36. Poly F, Wertz S, Brothier E, Degrange V. First exploration of Nitrobacter diversity in soils by a PCR cloning-sequencing approach targeting functional gene nxrA. FEMS Microbiol Ecol. 2008;63:132-40.

37. Lane DJ. 16/23S rRNA sequencing. In: Stackebrandt E, Goodfellow M, editors. Nucleic acid techniques in bacterial systematics. Chichester, UK: John Wiley \& Sons; 1991. p. 115-71.

38. Ludwig W, Strunk O, Westram R, Richter L, Meier H, Yadhukumar A, et al. ARB: a software environment for sequence data. Nucleic Acids Res. 2004;32:1363-71.

39. Quast C, Pruesse E, Yilmaz P, Gerken J, Schweer T, Yarza P, et al. The SILVA ribosomal RNA gene database project: improved data processing and web-based tools. Nucleic Acids Res. 2013;41:D590-D596.

40. Herlemann DP, Labrenz M, Jürgens K, Bertilsson S, Waniek JJ, Andersson AF. Transitions in bacterial communities along the
$2000 \mathrm{~km}$ salinity gradient of the Baltic Sea. ISME J. 2011;5:1571-9.

41. Caporaso JG, Lauber CL, Walters WA, Berg-Lyons D, Lozupone CA, Turnbaugh PJ, et al. Global patterns of 16S rRNA diversity at a depth of millions of sequences per sample. Proc Natl Acad Sci. 2011;108:4516-22.

42. Caporaso JG, Kuczynski J, Stombaugh J, Bittinger K, Bushman FD, Costello EK, et al. QIIME allows analysis of high-throughput community sequencing data. Nat Methods. 2010;7:335-6.

43. Dowd SE, Sun Y, Wolcott RD, Domingo A, Carroll JA. Bacterial tag-encoded FLX amplicon pyrosequencing (bTEFAP) for microbiome studies: Bacterial diversity in the ileum of newly weaned Salmonella-infected pigs. Foodborne Pathog Dis. 2008;5:459-72.

44. Bushnell B. BBMap short read aligner. Berkeley, CA.: University of California; 2016. http://sourceforge.net/projects/bbmap.

45. Nikolenko SI, Korobeynikov AI, Alekseyev MA. BayesHammer: Bayesian clustering for error correction in single-cell sequencing. BMC Genomics. 2013;14:S7.

46. Nurk S, Meleshko D, Korobeynikov A, Pevzner PA. MetaSPAdes: a new versatile metagenomic assembler. Genome Res. 2017;27:824-34.

47. Li H, Durbin R. Fast and accurate long-read alignment with Burrows-Wheeler transform. Bioinformatics. 2010;26:589-95.

48. Li H, Handsaker B, Wysoker A, Fennell T, Ruan J, Homer N, et al. The sequence alignment/map format and SAMtools. Bioinformatics. 2009;25:2078-9.

49. Graham ED, Heidelberg JF, Tully BJ. BinSanity: unsupervised clustering of environmental microbial assemblies using coverage and affinity propagation. PeerJ. 2017;5:e3035.

50. Lu YY, Chen T, Fuhrman JA, Sun F, Sahinalp C. COCACOLA: binning metagenomic contigs using sequence COmposition, read CoverAge, CO-alignment and paired-end read LinkAge. Bioinformatics. 2017:33:791-8.

51. Alneberg J, Bjarnason BS, De Bruijn I, Schirmer M, Quick J, Ijaz $\mathrm{UZ}$, et al. Binning metagenomic contigs by coverage and composition. Nat Methods. 2014;11:1144-6.

52. Wu YW, Simmons BA, Singer SW. MaxBin 2.0: An automated binning algorithm to recover genomes from multiple metagenomic datasets. Bioinformatics. 2015;32:605-7.

53. Kang DD, Froula J, Egan R, Wang Z. MetaBAT, an efficient tool for accurately reconstructing single genomes from complex microbial communities. PeerJ. 2015;3:e1165.

54. Sieber CMK, Probst AJ, Sharrar A, Thomas BC, Hess M, Tringe $\mathrm{SG}$, et al. Recovery of genomes from metagenomes via a dereplication, aggregation and scoring strategy. Nat Microbiol. 2018;3:836-43.

55. Parks DH, Imelfort M, Skennerton CT, Hugenholtz P, Tyson GW. CheckM: assessing the quality of microbial genomes recovered from isolates, single cells, and metagenomes. Genome Res. 2015;25:1043-55.

56. Seemann T. Prokka: rapid prokaryotic genome annotation. Bioinformatics. 2014;30:2068-9.

57. Altschul SF, Gish W, Miller W, Myers EW, Lipman DJ. Basic local alignment search tool. J Mol Biol. 1990;215:403-10.

58. Moriya Y, Itoh M, Okuda S, Yoshizawa AC, Kanehisa M. KAAS: an automatic genome annotation and pathway reconstruction server. Nucleic Acids Res. 2007;35:W182-W185.

59. Guindon S, Delsuc F, Dufayard JF, Gascuel O. Estimating maximum likelihood phylogenies with PhyML. Methods Mol Biol. 2009;537:113-37.

60. Ronquist F, Huelsenbeck JP. MrBayes 3: Bayesian phylogenetic inference under mixed models. Bioinformatics. 2003;19:1572-4.

61. Stamatakis A. RAxML version 8: a tool for phylogenetic analysis and post-analysis of large phylogenies. Bioinformatics. 2014;30:1312-3. 
62. Na SI, Kim YO, Yoon SH, Ha Smin, Baek I, Chun J. UBCG: Upto-date bacterial core gene set and pipeline for phylogenomic tree reconstruction. J Microbiol. 2018;56:281-5.

63. Olm MR, Brown CT, Brooks B, Banfield JF. DRep: a tool for fast and accurate genomic comparisons that enables improved genome recovery from metagenomes through de-replication. ISME J. 2017;11:2864-8.

64. Lagkouvardos I, Joseph D, Kapfhammer M, Giritli S, Horn M, Haller D, et al. IMNGS: a comprehensive open resource of processed 16S rRNA microbial profiles for ecology and diversity studies. Sci Rep. 2016;6:33721.

65. Dodsworth JA, Gevorkian J, Despujos F, Cole JK, Murugapiran SK, Ming H, et al. Thermoflexus hugenholtzii gen. nov., sp. nov., a thermophilic, microaerophilic, filamentous bacterium representing a novel class in the Chloroflexi, Thermoflexia classis nov., and description of Thermoflexaceae fam. nov. and Thermoflexales ord. nov. Int J Syst Evol Microbiol. 2014;64:2119-27.

66. Jackson TJ, Ramaley RF, Meinschein WG. Thermomicrobium, a new genus of extremely thermophilic bacteria. Int J Syst Bacteriol. 1973;23:28-36.

67. King CE, King GM. Thermomicrobium carboxidum sp. nov., and Thermorudis peleae gen. nov., sp. nov., carbon monoxideoxidizing bacteria isolated from geothermally heated biofilms. Int J Syst Evol Microbiol. 2014;64:2586-92.

68. Herbold CW, Lee CK, McDonald IR, Cary SC. Evidence of global-scale aeolian dispersal and endemism in isolated geothermal microbial communities of Antarctica. Nat Commun. 2014;5:1-10.

69. Meincke M, Bock E, Kastrau D, Kroneck PMH. Nitrite oxidoreductase from Nitrobacter hamburgensis: redox centers and their catalytic role. Arch Microbiol. 1992;158:127-31.

70. Lücker S, Wagner M, Maixner F, Pelletier E, Koch H, Vacherie B, et al. A Nitrospira metagenome illuminates the physiology and evolution of globally important nitrite-oxidizing bacteria. Proc Natl Acad Sci. 2010;107:13479-84.

71. Kirstein K, Bock E. Close genetic relationship between Nitrobacter hamburgensis nitrite oxidoreductase and Escherichia coli nitrate reductases. Arch Microbiol. 1993;160:447-53.

72. Kitzinger K, Koch H, Lücker S, Sedlacek CJ, Herbold C, Schwarz J, et al. Characterization of the first "Candidatus Nitrotoga" isolate reveals metabolic versatility and separate evolution of widespread nitrite-oxidizing bacteria. mBio. 2018;9:1-16.

73. Anantharaman K, Brown CT, Hug LA, Sharon I, Castelle CJ, Probst AJ, et al. Thousands of microbial genomes shed light on interconnected biogeochemical processes in an aquifer system. Nat Commun. 2016;7:1-11.

74. Hedlund BP, Dodsworth JA, Murugapiran SK, Rinke C, Woyke $\mathrm{T}$. Impact of single-cell genomics and metagenomics on the emerging view of extremophile "microbial dark matter". Extremophiles. 2014;18:865-75.

75. Takami H, Noguchi H, Takaki Y, Uchiyama I, Toyoda A, Nishi S, et al. A deeply branching thermophilic bacterium with an ancient acetyl-CoA pathway dominates a subsurface ecosystem. PLoS ONE. 2012;7.

76. Nunoura T, Takaki Y, Kakuta J, Nishi S, Sugahara J, Kazama H, et al. Insights into the evolution of Archaea and eukaryotic protein modifier systems revealed by the genome of a novel archaeal group. Nucleic Acids Res. 2011;39:3204-23.

77. Hugenholtz P, Stackebrandt E. Reclassification of Sphaerobacter thermophilus from the subclass Sphaerobacteridae in the phylum Actinobacteria to the class Thermomicrobia (emended description) in the phylum Chloroflexi (emended description). Int J Syst Evol Microbiol. 2004;54:2049-51.

78. Rodriguez-R LM, Konstantinidis KT. The enveomics collection: a toolbox for specialized analyses of microbial genomes and metagenomes. 2016.

79. Daims H, Lücker S, Le Paslier D, Wagner M. Diversity, environmental genomics, and ecophysiology of nitrite-oxidizing bacteria. In: Ward BB, Klotz MG, Arp DJ, editors. Nitrification. Washington, DC, USA: ASM Press; 2011. p. 295-322.

80. Bock E. Growth of Nitrobacter in the presence of organic matter. Arch Microbiol. 1976;108:305-12.

81. Lipski A, Spieck E, Makolla A, Altendorf K. Fatty acid profiles of nitrite-oxidizing bacteria reflect their phylogenetic heterogeneity. Syst Appl Microbiol. 2001;24:377-84.

82. Kim J-G, Park S-J, Sinninghe Damsté JS, Schouten S, Rijpstra WIC, Jung M-Y, et al. Hydrogen peroxide detoxification is a key mechanism for growth of ammonia-oxidizing archaea. Proc Natl Acad Sci. 2016;113:7888-93.

83. Nunoura T, Chikaraishi Y, Izaki R, Suwa T, Sato T, Harada T, et al. A primordial and reversible TCA cycle in a facultatively chemolithoautotrophic thermophile. Science. 2018;359:559-63.

84. Mall A, Sobotta J, Huber C, Tschirner C, Kowarschik S, Bačnik $\mathrm{K}$, et al. Reversibility of citrate synthase allows autotrophic growth of a thermophilic bacterium. Science. 2018;359:563-7.

85. Pati A, la Butti K, Pukall R, Nolan M, del Rio TG, Tice H, et al. Complete genome sequence of Sphaerobacter thermophilus type strain (S 6022 T). Stand Genom Sci. 2010;2:49-56.

86. Yabe S, Aiba Y, Sakai Y, Hazaka M, Yokota A. A life cycle of branched aerial mycelium- and multiple budding spore-forming bacterium Thermosporothrix hazakensis belonging to the phylum Chloroflexi. J Gen Appl Microbiol. 2010;56:137-41.

87. Filippidou S, Junier T, Wunderlin T, Kooli WM, Palmieri I, AlDourobi A, et al. Adaptive strategies in a poly-extreme environment: differentiation of vegetative cells in Serratia ureilytica and resistance to extreme conditions. Front Microbiol. 2019;10:1-13.

88. Suzina NE, Mulyukin AL, Kozlova AN, Shorokhova AP, Dmitriev VV, Barinova ES, et al. Ultrastructure of resting cells of some nonspore-forming bacteria. Microbiology. 2004;73:435-47.

89. Meyer-Dombard DR, Swingley W, Raymond J, Havig J, Shock EL, Summons RE. Hydrothermal ecotones and streamer biofilm communities in the Lower Geyser Basin, Yellowstone National Park. Environ Microbiol. 2011;13:2216-31.

90. Yamada T, Sekiguchi Y. Cultivation of uncultured chloroflexi subphyla: significance and ecophysiology of formerly uncultured chloroflexi 'subphylum i' with natural and biotechnological relevance. Microbes Environ. 2009;24:205-16.

91. Miller SR, Strong AL, Jones KL, Ungerer MC. Bar-coded pyrosequencing reveals shared bacterial community properties along the temperature gradients of two alkaline hot springs in Yellowstone National Park. Appl Environ Microbiol. 2009;75:4565-72.

92. Watsuji T, Kato T, Ueda K, Beppu T. CO2 supply induces the growth of Symbiobacterium thermophilum, a syntrophic bacterium. Biosci Biotechnol Biochem. 2006;70:753-6.

93. Stewart EJ. Growing unculturable bacteria. J Bacteriol. 2012;194:4151-60.

94. Overmann J, Abt B, Sikorski J. Present and future of culturing bacteria. Annu Rev Microbiol. 2017;71:711-30.

95. Inskeep W. The YNP metagenome project: environmental parameters responsible for microbial distribution in the Yellowstone geothermal ecosystem. Front Microbiol. 2013;4:1-15. 